\title{
ЯЗЫКОВЫЕ ОСОБЕННОСТИ ЗАГОЛОВКОВ НЕМЕЦКИХ ГАЗЕТ И ИХ УЧЕТ ПРИ ПЕРЕВОДЕ
}

\author{
С. В. Евтеев
}

\author{
Московский государственный институт международных отночений (университет)
}

\section{LANGUAGE FEATURES OF GERMAN NEWSPAPER HEADLINES AND SPECIFICS OF THEIR TRANSLATION}

\author{
S. V. Evteev \\ Moscow State Institute of International Relations (University)
}

\begin{abstract}
Аннотация: газетные заголовки обладают рядом грамматических, синтаксических и стилистических особенностей, что связано с их коммуникативными функциями. Заголовок рассматривается как особая коммуникативная и лингвистическая единица, как тип текста с содержательными и языковыми особенностями, что представляет несомненный интерес для филологического исследования. Целью статьи является анализ языковой структуры и особенностей немеиких газетных заголовков, их описание и учет при переводе с немеикого языка на русский и наоборот. В ходе исследования методом сплошной выборки с последуюшим использованием описательного метода, классификацией и обобщением материалов было отобрано и проанализировано более 1500 заголовков четырех немецких онлайн-изданий, рассчитанных на массового читателя. Синтаксические особенности немеикого газетного заголовка связаны с его длиной и экономией языковых средств. Это находит свое выражение в употреблении простых повествовательных предложений, эллиптических конструкций, номинальных фраз и m. n. Грамматические особенности немецкого газетного заголовка характеризуются возможным опущением таких частей предложения, как артикли, глаголь-связки, союзы, притяжательные и личные местоимения и т. п. Стилистические особенности заголовков связаны с выражением экспрессивности, с эмоциональным воздействием на читателя, для чего используются идиоматика, авторские стилистические фигуры, прецедентные выражения, пословицы, поговорки. В работе перечислены основные трудности, с которыми может столкнуться переводчик при передаче немецких газетных заголовков. Результаты проведенного анализа будут полезны для дальнейших исследований газетно-публицистического дискурса, использования на теоретических и практических занятиях по переводу медиатекстов.

Ключевые слова: газетный заголовок, немеияий язык, грамматические, синтаксические и стилистические особенности заголовка, перевод.
\end{abstract}

\begin{abstract}
: newspaper headlines have quite a number of grammatical, syntactic and stylistic features connected with their communicative functions. A headline is regarded as a specific communicative and linguistic unit, a type of a text with content and language features, which is of undoubted interest for a philological research. The article is aimed at analyzing the language structure and the peculiarities of German newspaper headlines, and their description to be considered in translation from German into Russian and in reverse. The research, with continuous sampling methods used and followed by a descriptive method, classification and generalization of the materials, included more than 1500 headlines from four German online-publications targeted at a mass reader. The syntactic peculiarities of a German newspaper headline are connected with its length and the economy of language means. It finds its reflection in the use of simple declarative sentences, elliptical constructions, nominal phrases, etc. The grammatical features of a German newspaper headline are characterized by a possible omission of such parts of the sentence as articles, linking verbs, conjunctions, possessive and personal pronouns, etc. The stylistic peculiarities of headlines are connected with expressivity, creation of emotional impact on the reader, to which end idiomatic phrases, authors' stylistic figures, precedent phrases, proverbs and sayings are used. The article manifests the
\end{abstract}

(C) Евтеев С. В., 2021 
main difficulties a translator may face in translating German newspaper headlines. The results of the research may be of use for a further study of a newspaper discourse, in theoretical and practical classes on media text translation.

Key words: newspaper headline, the German language, grammatical, syntactical and stylistic peculiarities of a headline, translation.

\section{Введение}

В работе рассматриваются заголовки текстов в немецком политическом медиадискурсе, их функциональные и языковые особенности для последующей выработки переводческих решений при их передаче. В качестве объекта исследования выбраны заголовки немецких новостных онлайн-изданий, рассчитанных на массового читателя. Предметом изучения являются синтаксические, грамматические, стилистические особенности указанных заголовков.

Толковые словари определяют понятие «заголовок (заглавие)» как «название какого-н. произведения (литературного, музыкального) или отдельных его частей» [1, с. 311], «заглавие книги или какой-либо ее части, газетной, журнальной и др. публикации» [2, c. 662].

Заголовок призван в краткой и понятной форме привлечь и удержать внимание читателя. Для подобного речевого воздействия необходим тщательный отбор языковых средств. Специфика коммуникативных функций, языковых средств и структуры позволяет рассматривать заголовок как особую коммуникативную и лингвистическую единицу, связанную с текстом сообщения.

Основные функции заголовка:

- информирование потенциального читателя с помощью минимального объема предваряющей информации о содержании текста сообщения;

- упрощение отбора интересующих читателя статей по тематике, жанру и стилю публикаций;

- достижение предварительного оценочно-эмоционального воздействия с тем, чтобы подготовить, а затем и убедить читателя в правильности выводов автора публикации;

- оказание влияния на сознание и образ мыслей читателя и, таким образом, закрепление в памяти читателя содержания сообщения.

Функции заголовка в сочетании с их определенными моделями в разных рубриках газетных статей, отвечающих интересам различных групп читателей, свидетельствует о том, что заголовок - это сложный, комплексный феномен. Заголовок, как разновидность текста, обладает специфическими текстовыми признаками и конвенционализированным способом языковой коммуникации, что, в свою очередь, связано с соответствующими коммуникативными задачами. Как коммуникативная единица заголовок представляет собой особый тип текста с содержательны- ми (микротекст по объему), синтаксическими, грамматическими, стилистическими особенностями, а также особенностями внеязыкового оформления (размещения в тексте, выбора шрифта и т. п.).

\section{Материалы и методы}

Методом сплошной выборки было отобрано и проанализировано более 1500 заголовков политических статей четырех немецких онлайн-газет Frankfurter Allgemeine Zeitung (далее FAZ), Bild, Süddeutsche Zeitung (SZ), Die Welt (Welt) за февральапрель 2021 г. Выбор онлайн-газет связан с доступностью электронных ресурсов и архивов, что облегчает поиск и обработку материалов. При этом использовался описательный метод с классификацией и обобщением материалов.

Результаты проведенного анализа могут быть использованы для дальнейших теоретических исследований газетно-публицистического дискурса и закономерностей функционирования газетных заголовков на немецком языке, а выявление и учет грамматической, синтаксической и стилистической специфики заголовков - на практических занятиях по переводу медиатекстов.

\section{Результаты исследования}

Анализ синтаксической структуры позволяет говорить об особой текстовой организации заголовков, заключающейся в краткости и экономии языковых средств. Ограниченное количество слов в заголовке дает возможность читателю легко и быстро охватить взглядом суть сообщения. Это находит свое выражение в использовании простых повествовательных предложений, эллиптических конструкций, номинальных фраз, сокращений и т. п. При этом для выполнения своей когнитивной функции ограниченное количество используемых языковых средств не должно влиять на понимание содержания читателем. Как правило, длина заголовка меньше, чем длина предложения текстового сообщения. Длина немецкого газетного заголовка в среднем составляет 30 печатных знаков без пробелов [3, S. 1] или не более 50 знаков с пробелами [4, S. 34].

Помимо простых повествовательных предложений, для большей экспрессии могут употребляться заголовки в форме восклицательных и вопросительных предложений, союзных придаточных предложений (без главного предложения) с обратным порядком слов, например: 
Söder wittert „Wechselstimmung“ (Bild oт 28.03.2021);

Opposition fordert Rücktritte (SZ от 29.03.2021);

Österreich droht mit Impfstoff-Blockade (FAZ oт 31.03.2021);

Haftbefehl in der Masken-Affäre! (Bild oт 25.03.2021);

Droht uns jetzt ein Impfstoff-Krieg? (Bild от 25.03.2021);

Warum Rechtspopulisten in Stockholm bald mehr Macht haben (FAZ от 23.03.2021);

Wie Bürgermeister sich gegen Laschets Schulöffnung wehren (Welt от 24.03.2021);

Warum es die Zeitumstellung noch gibt ( $\mathrm{SZ}$ от 25.03.2021).

Привлекательность вопросительных предложений в качестве заголовков заключается, по мнению журналистов, в желании читателя получить ответ на поставленный в заголовке вопрос, прочитав сообщение.

Экономить языковые средства в заголовке позволяют конструкции с двоеточием. Двоеточие отделяет левую сторону, в которой в сокращенной форме обозначается источник информации (институциональный или персональный), название события или его причина, от правой стороны, где приводится краткая цитата или последствие события [5, S. 305-306], например:

Bartsch: Merkel soll Vertrauensfrage stellen (FAZ 25.03.2021);

Minister appelliert an Bevölkerung: Urlaub verschieben ( $\mathrm{SZ}$ от 22.03.2021);

Gas-Streit mit Polen: Deutschland droht Niederlage vor EuGH (SZ 18.03.2021);

Biden über Kims Raketentest: „Alles wie gehabt ...“ (Bild от 24.03.2021).

Двоеточие в некоторых изданиях заменяется на тире с сохранением указанных конструкций, например:

Kanzlerfrage in der Union - ,Markus Söder hat einen großen Vorteil“" (Welt от 08.04.2021);

„Unamerikanisch“-Corona-Impfausweis spaltet die USA (Welt от 08.04.2021);

Digitale Gesundheit - wo wir stehen (SZ от 07.02.2021);

Wegen Falschzitat - Künast will Grundsatzurteil gegen Facebook erwirken (Welt от 27.04.2021).

Требования краткости, ясности и простоты заголовков находят свое отражение и в особенностях грамматических конструкций. Грамматика заголовков может отличаться от принятых норм грамматики немецкого языка. Поскольку такие отличия связаны со спецификой функционирования заголовков, читателем в данной коммуникативной ситуации грамматические отклонения или нарушения воспринимают- ся как само собой разумеющиеся. С одной стороны, понимание подобных грамматически неправильных предложений (фраз) входит в пассивную компетенцию читателя. С другой стороны, заголовки, построенные правильно с точки зрения норм грамматики языка, могут свидетельствовать о недостаточной компетенции автора текста. Для сокращения количества языковых средств используются эллиптические заголовочные конструкции. В них опускаются части предложения, которые не влияют на понимание содержания. Такие части предложения, как артикли, глаголы-связки, союзы, притяжательные и личные местоимения, читатель может легко восстановить по смыслу, например:

Bundespräsident mit Astra-Zeneca geimpft (FAZ oт 01.04.2021);

Deutschland geht in verschärften fünftägigen Oster-Lockdown (FAZ от 23.03.2021);

Union stürzt in Umfrage ab (SZ от 26.03.2021);

FDP legt Verfassungsbeschwerde gegen „Corona-Notbremse" ein (FAZ от 27.04.2021);

Bundesregierung prüft Unterbindung von Urlaubsreisen ins Ausland (Welt oт 24.03.2021);

Linke pochen auf Moratorium für Abschiebung wegen Pandemie (SZ от 25.03.2021);

Bundesregierung stuft Niederlande nach Ostern als Hochinzidenzgebiet ein (Welt от 05.04.2021);

Entschuldigung angenommen, Frau Kanzlerin (Bild от 24.03.2021);

Grünen-Fraktionschefin hofft auf Corona-Modellregion ( $\mathrm{SZ}$ от 23.03.2021).

Номинальные фразы, состоящие из существительных с предлогами или без них, с согласованными или несогласованными определениями, также позволяют более концентрированно передавать информацию, существенно экономить языковые средства, избегать придаточных предложений. В номинальных фразах зачастую отсутствует артикль. Однако и здесь имеется своя регулярность. В заголовках остаются артикли в тех случаях, когда их отсутствие может привести к неправильному пониманию связи слов в предложении и содержания, например:

Historische Gedächtnislücke (FAZ от 25.03.2021);

Merkel für Förderung von Integration (FAZ от 09.03.2021);

Scharfe Kritik von Unternehmern an Corona-Beschlüssen ( $\mathrm{SZ}$ от 23.03.2021);

Kritik der Grünen an deutscher Qatar-Politik (FAZ от 07.03.2021).

В заголовках вербального стиля для придания актуальности и живости событиям, которые происходили в прошлом, часто используется настоящее время (презенс). Подобный прием приближения действий к настоящему времени известен читателям и не вызывает у них проблем в понимании времени 
описываемых событий. В Швейцарии и Австрии более распространены в этом случае заголовки в имперфекте (прошедшем времени). При употреблении заголовков в вербальном стиле, предполагающем частотное употребление глагольных форм, глагольных оборотов и придаточных предложений, зачастую используется активный залог. Для заголовков в пассивном залоге характерно опущение глаголов-связок, например:

Kabinett billigt Einsatzverlängerung bis 2022 (FAZ от 24.02.2021);

SPD-Politiker zieht Kandidatur für Bundestag zurück (Bild от 24.03.2021);

Noch nicht geimpft und schwer erkrankt (SZ oT 22.03.2021);

Chinas Botschafter zu Gespräch ins Auswärtige Amt geladen (FAZ от 23.03.2021);

Regierung erspart sich nächste Blamage (Bild oT 25.03.2021);

Union nach Umfragetief leicht verbessert, SPD verliert (Welt от 04.04.2021).

Для большего прагматического потенциала в заголовках используется измененный порядок слов. В этом случае на первое место для акцентирования внимания читателя выносится наиболее важный член предложения. Им может быть часть сказуемого, наречие, дополнение и т. п., например:

Über dieses Papier streiten sie jetzt! (Bild oт 22.03.2021);

Deutschland droht die Vollbremsung (Bild ot 20.03.2021);

Deutlich mehr Drogentote in Deutschland während Pandemie (FAZ от 25.03.2021);

Emotional wird Schäuble beim Thema EU (SZ OT 29.03.2021).

Стилистические особенности заголовков связаны с выражением экспрессивности, эмоциональным воздействием на читателя с тем, чтобы не только его информировать, но и привлечь внимание к публикации, заинтересовать и настроить на определенное восприятие публикации. Для этого употребляются такие стилистические средства, как метафоры, идиомы, аллюзии, аллегории, каламбуры, игра слов и т. п. Подобные стилистические средства в сочетании с реалиями представляют собой особую сложность для перевода и понимания у читателей с иным объемом фоновых знаний. Дополнительной проблемой в переводе является объем заголовка, в котором невозможно дать комментарий, необходимую фоновую информацию, например:

Wie versprochen, so gebrochen (Welt от 29.03.2021);

Putin und Biden: Streiterei auf dem Hinterhof (SZ от 20.03.2021);

Altenpflege: Allein im Heim (SZ от 19.03.2021);

Jeder kämpft jetzt für sich allein (Welt от 30.03.2021);
Jedem sein Schlupfloch (SZ oт 29.03.2021);

Chinas neuer Buhmann heißt Europa (Welt oт 07.04.2021).

Проведенный анализ указанных изданий показал, что в качестве заголовков на простые повествовательные предложения полного состава (т. е. без опущения артиклей, глаголов-связок, местоимений и т. п.) в среднем приходится $16,4 \%$, в частности в FAZ 13,9 \%, SZ - 14,6 \%, Welt - 19,4 \%, Bild - 17,5 \%. Простые повествовательные предложения с опущением артикля в заголовках в среднем составляют $28,1 \%$, в частности в FAZ - $21 \%$, SZ - 33,5 \%, Welt - $33 \%$, Bild - 24,8 \%. Заголовки в пассивном залоге с опущением глаголов-связок употребляются сравнительно редко - в среднем в 3,2 \% всех заголовков, в частности в FAZ - 2,4 \%, SZ - 3,3\%, Welt - 5,2 \%, Bild $-1,9 \%$.

В употреблении вопросительных предложений в качестве заголовков и заголовков с восклицательным знаком наблюдается значительное количественное расхождение. Так, при среднем использовании вопросительного знака в заголовках около 7,3 \%, в FAZ подобные заголовки составляют 4,8 \%, SZ - около $3 \%$, Welt - 5,6 \%, а в Bild - 15,6 \%. Использование восклицательного знака в заголовках отмечено в FAZ $-2,8 \%$ и в Bild - 8,3 \% (в SZ и Welt практически не употребляется). Значительное количественное расхождение отмечается и в употреблении двоеточия и тире в заголовках: двоеточие в FAZ - 3,2 \%, SZ 3,3\%, Welt - практически не употребляется, Bild $7,6 \%$, а тире практически не употребляется в FAZ и SZ, но в Welt - $12,7 \%$, в Bild - около $2 \%$.

На союзные придаточные предложения (без главного предложения) с обратным порядком слов приходится в среднем около $6,3 \%$, в частности в FAZ подобные конструкции отмечены в $6 \%$ заголовков, $\mathrm{SZ}-7,7 \%$, Welt $-5,7 \%$, Bild - 5,7\%.

Номинальные конструкции представляют собой наиболее распространенную разновидность заголовков. В среднем они составляют $28,6 \%$ от общего количества, в частности в $\mathrm{FAZ}-44,8 \%, \mathrm{SZ}-32,7 \%$, Welt - 19,2 \%, Bild - 17,5\%.

\section{Особенности перевода заголовков}

Языковые и функциональные особенности заголовка должны предусматривать и особый подход к его переводу. Практика перевода подтверждает тот факт, что передача заголовков на другой язык зачастую намного сложнее перевода самого сообщения, поскольку приходится учитывать языковую специфику заголовка, фоновые знания адресной группы реципиентов в другой культуре, возможности привлечения их внимания и эмоционального воздействия. Чтобы выполнить эти требования к переводу заголовка, недостаточно «сказать почти то же самое» на 
другом языке с сохранением структурно-семантической эквивалентности. Расхождение с оригиналом может быть значительным.

Для выполнения качественного перевода необходимо знание и учет совокупности функциональных и языковых особенностей заголовков, которые в разных языках и культурах могут иметь как сходства, так и различия. Языковое оформление заголовков представляет собой лингвокультурный продукт с принятыми в данном языковом сообществе правилами и возможными отклонениями от языковой нормы. Если функциональная направленность заголовка (в нашем случае в немецком и русском языках) в целом идентична, то ее реализация может иметь языковые особенности. Эти особенности при переводе как с немецкого, так и с русского языков оказывают влияние на процесс и результат перевода. Не останавливаясь на переводе конкретных заголовков, отметим общие правила и проблемы при их передаче, а также рекомендации по устранению возможных проблем.

Как уже было отмечено, во многих немецких газетных заголовках отмечаются специфические структурные черты, связанные с опущением членов предложения. Для переводчика это означает необходимость мысленного восстановления пропущенных языковых элементов для понимания предложения (фразы) и последующего перевода. В свою очередь при переводе заголовка на немецкий язык производится анализ языковых средств, которые можно опустить без ущерба для понимания содержания и для достижения необходимого эмоционального эффекта.

Специфической чертой заголовков в обоих рассматриваемых языках является его длина. Средняя длина немецкого газетного заголовка составляет 30 знаков без учета пробелов или 50 знаков с пробелами. Средняя длина подобного заголовка на русском языке составляет $7+2$ слова (из расчета средней длины слова 6 знаков) [6], т. е. около 60 знаков, в 2 раза больше. Заголовки из 10 слов и более воспринимаются хуже коротких [7, с. 179]. При быстром просмотре газетного заголовка есть полторы секунды для привлечения внимания среднего читателя. На такое время задерживается его внимание на заголовке [8].

Это означает, что при переводе для производства определенного эффекта на читателя необходимо подбирать адекватную форму заголовка, «уложив» в нее нужное содержание и выразительные средства. Большая длина заголовка при переводе на немецкий язык может привести к нарушению правила объема заголовка с последующим «отторжением» со стороны реципиента и, как следствие, к отсутствию нужного эффекта. Безусловно, эффект достигается не только за счет длины заголовков. Однако из-за незнания подобного правила в практике и в процессе обучения переводу нередко встречаются неадекватные переводческие решения. Зачастую это связано со стремлением переводчика вместить в рамки переводного заголовка дополнительную разьясняющую информацию из-за расхождений в фоновых знаниях реципиентов в разных лингвокультурных сообществах. Если для ознакомительного перевода такой подход возможен, то для перевода с целью дальнейшей газетной публикации - нет.

Приведем пример из переводческой практики. Заголовок в онлайн-газете FAZ (от 13.12.2017) «Flüchtlingsquoten, Abgasskandal und Scharia-Polizei»" (51 знак) переведен «Квоть на распределение беженцеев по странам Евросоюза, скандал вокруг кониерна Фольксваген, связанный с занижсением уровня вылорсов выхлопных газов при продажах автомобилей в США и Европе, и исламистский полицейский рейд в Германии» (229 знаков). Переводчик дал дополнительную информацию, чтобы разъяснить немецкие реалии, но не учел принятые правила оформления немецкого заголовка. Были нарушены лаконичность, образность и экспрессивность заголовка в переводе. Заголовок читается и воспринимается с трудом. Можно предложить сокращенный вариант перевода, например: «Квоты на беженцев, дизельный скандал и шариатская полиция» (57 знаков), а имеющиеся реалии разъяснить в самом тексте сообщения в виде дополнений или комментариев переводчика. Еще один пример из приложения российской газеты «Независимая» на немецком языке. Приложение печатает переводы текстов своих корреспондентов и представляет собой полезный ресурс для изучающих немецкий язык и переводчиков. Заголовок статьи «Россия и Евросоюз: быть вместе нельзя расстаться?» от 28.02.2021 (50 знаков) передан как «Russland und die Europäische Union - zusammen sein oder sich trennen?» (от 3.03.2021) - 69 знаков. В переводе, к сожалению, не удалось передать игры слов со знаками препинания. При этом заголовок без нарушения содержания можно было сократить до 41 знака - «Russland und EU - zusammen oder getrennt?» или до 37 знаков «Russland-EU-zusammen oder getrennt?».

Еще одной проблемой при переводе является передача стилистических особенностей заголовка и связанного с этим оценочно-эмоционального воздействия на читателя, привлечения его внимания. В процессе перевода это означает вначале нахождение в оригинале стилистических особенностей, затем выделение языковых средств реализации указанной функции и, наконец, определение языковых средств в другом языке для адекватной передачи заголовка. Для выбора выразительных средств в переводе не всегда достаточно ориентироваться только на оригинальный заголовок. Необходимо принимать во вни- 
мание содержание всего сообщения. Особую трудность представляют собой индивидуальные, авторские стилистические фигуры, рифмованные выражения, прецедентные выражения, хорошо известные в исходной культуре, но неизвестные в переводной культуре (например, фразы национальных политических деятелей, фразы из книг, кинофильмов, пословицы, поговорки и т. п.). В этом случае адекватный перевод будет ориентирован на содержание сообщения и может обнаруживать значительные лексико-семантические и структурные расхождения с оригиналом.

Например, рифмованный газетный заголовок "Voller Tücke in die Brücke eine Lücke" (FAZ oт 09.04.2021) (дословно: «полные коварства, делают дыру в мосту») из стихов для детей Вильгельма Буша «Макс и Мориц» о двух шалунах. В известном переводе на русский язык 1890 г. эти строки передаются как «Вскочили дети на мостки И подпилили полдо$c \kappa u »$. В газетной статье речь идет о том, что одни политические партии в сложных условиях пандемии и различных ограничений вносят предложения, а другие партии и их представители сходу, без аргументации отвергают эти предложения. Возможный перевод заголовка: «Одни созидают, другие ломают» или «Одни стремятся созидать, другие - разрушать».

\section{Заключение}

Заголовок представляет собой особую коммуникативную и лингвистическую единицу, связанную с его функцией привлекать и удерживать внимание читателей в краткой, доступной и зачастую эмоциональной форме. Подобное речевое воздействие предполагает тщательный отбор языковых средств, особое языковое и внеязыковое оформление.

Особое языковое оформление заголовков политических статей немецких онлайн-газет находит отражение в синтаксических, грамматических, стилистических особенностях. Это позволяет говорить о заголовке как о сложном феномене и типе текста, нередко требующем при переводе значительных трансформаций.

Синтаксические особенности заголовка заключаются в использовании ограниченного количества языковых средств, что находит выражение в употреблении простых повествовательных предложений, эллиптических конструкций, номинальных фраз, сокращений и т. п. Для акцентирования внимания читателя в заголовках используется измененный порядок слов, когда на первое место выносится наиболее важный член предложения. Средняя длина немецкого газетного заголовка составляет 30 знаков, а подобного заголовка на русском языке - около 60 знаков.

Грамматические особенности немецкого газетного заголовка характеризуются возможным опущением частей предложения, которые читатель может восстановить по смыслу: глаголов-связок, артиклей, союзов, притяжательных и личных местоимений и т. п.

Стилистические особенности заголовков связаны с выражением экспрессивности, эмоциональным воздействием на читателя, для чего используется идиоматика, авторские стилистические фигуры, прецедентные выражения, пословицы, поговорки и т. п.

Структурные и языковые особенности заголовка должны быть знакомы переводчику, учитываться им, творчески и адекватно передаваться реципиентам другого лингвокультурного сообщества.

Тема передачи заголовков должна присутствовать в тематике переводческой подготовки для повышения уровня переводческой компетенции.

\section{ЛИТЕРАТУРА}

1. Ожегов С. И. Толковый словарь русского языка : около 100000 слов, терминов и фразеологических выражений / под ред. Л. И. Скворцова. 27-е изд., испр. М. : АСТ : Мир и Образование, 2019. 1360 с.

2. Скворияов Л. И. Большой толковый словарь правильной русской речи : 8000 слов и выражений. М. : Оникс, 2009. 1104 с.

3. Esslinger D., Schneider W. Die Überschrift: Sachzwänge - Fallstricke - Versuchungen - Rezepte, 5. Auflage. Wiesbaden (Springer VS). Herausgeber : Springer VS; 5 ., aktualisierte und erweiterte Aufl. 2015 Edition (21. Januar 2015) Sprache : Deutsch Taschenbuch, $178 \mathrm{~S}$.

4. Fischer Ch. M. Macht Schlagzeilen! - 1.000 PRIdeen, um Kunden und Journalisten für Ihr Unternehmen zu gewinnen. Gabal Verlag, Offenbach 2009. 428 S.

5. Kurz J. et al. Stilistik für Journalisten, 2., erw. u. überarb. Aufl., Verlag: VS Verlag für Sozialwissenschaften, 2010. S. 369.

6. Дмитриева Л. Что в заголовке твоем : рекомендации по созданию эффективных заголовков. URL: https://www.ippnou.ru/print/ 05206/

7. Сохова И. Б. Рекламный заголовок и его функции // Молодой ученый. 2018. № 52 (238). С. 178-179. URL: https://www.moluch.ru/archive/238/55281/

8. Назайкин A. Заголовок (заглавие) в тексте копирайтера. URL: http://www.nazaykin.ru/lekcii/copywriting/ sozdanie_texta/zagolovok.htm

\section{REFERENCES}

1. Ozhegov S. I. Tolkovy slovar' russkogo yazyka: okolo 100000 slov, terminov i frazeologicheskikh vyrazheniy. Pod red. prof. L. I. Skvortsova. 27-e izd., ispr. [Thesaurus of the Russian language: about 100000 words, terms and phraseological units. Ed. pr. L. I. Skvortsov. 27-th ed.]. M.: Izdatelstvo AST: Mir i obrazovanie, 2019. $1360 \mathrm{p}$.

2. Skvortsov L. I. Bolshoy tolkovy slovar' pravilnoy russkoy rechi: 8000 slovi vyrazhenij [A large Explanatiry 
dictionary of correct Russian speech: 8000 words and expressions]. M. : Izdatelstvo Oniks, 2009. 1104 p.

3. Esslinger D., Schneider W. Die Überschrift: Sachzwänge - Fallstricke - Versuchungen - Rezepte, 5. Auflage. Wiesbaden (Springer VS). Herausgeber : Springer VS; 5., aktualisierte und erweiterte Aufl. 2015 Edition (21. Januar 2015) Sprache : Deutsch Taschenbuch. 178 S.

4. Fischer Ch. M. Macht Schlagzeilen! - 1.000 PRIdeen, um Kunden und Journalisten für Ihr Unternehmen zu gewinnen. Gabal Verlag, Offenbach 2009. 428 S.

5. Kurz J. et al. Stilistik für Journalisten, 2., erw. u. überarb. Aufl., Verlag: VS Verlag für Sozialwissenschaften, 2010. S. 369.

Московский государственный институт международных отношений (университет)

Евтеев С. В., кандидат филологических наук, доиеет, начальник Управления языковой подготовки и Болонского прочесса

E-mail:sergevt@inbox.ru

Поступила в редакциюю 14 сентября 20212.

Принята к публикации 15 октября 20212.

\section{Для цитирования:}

Евтеев С. В. Языковые особенности заголовков немецких газет и их учет при переводе // Вестник Воронежского государственного университета. Серия: Лингвистика и межкультурная коммуникация. 2021. № 4. C. 112-118. DOI: https://doi.org/10.17308/lic.2021.4/3818
6. Dmitrieva L. Chto v zagolovke tvoyom : rekomendatsii po sozdaniyu effektivnykh zagolovkov [What is there in your headline? recommendations on making effective headlines]. Available at: https:/www.ippnou. ru/print/ 05206/

7. Sokhova I. B. Reklamny zagolovok $i$ ego funktsii [Advertising title and its functions]. In: Molodoj Uchonyj. 2018. No. 52 (238). Pp. 178-179. Available at: https:// www.moluch.ru/archive/238/55281/

8. Nazaikin A. Zagolovok (zaglaviye) v tekste kopiraitera [The Headine (title) in the copywriter's text]. Available at: http://www.nazaykin.ru/lekcii/ copywriting/sozdanie_texta/ zagolovok.htm

Moscow State Institute of International Relations (University)

Evteev S. V., Candidate of Philology, Associate Professor, Head of the Language Training and Bologna Process Directorate

E-mail:sergevt@inbox.ru

Received: 14 September 2021

Accepted: 15 October 2021

\section{For citation:}

Evteev $S$. $V$. Language features of German newspaper headlines and specifics of their translation. Proceedings of Voronezh State University. Series: Linguistics and Intercultural Communication. 2021. No. 4. Pp. 112-118. DOI: https://doi.org/10.17308/lic.2021.4/3818 